\title{
Small Bowel Ischemia in a Sickle Cell Patient
}

\author{
Shabirhusain S. Abadin Mario R. Salazar Richard Y. Zhu \\ Mark M. Connolly Francis J. Podbielski \\ Department of Surgery, Saint Joseph Hospital, Chicago, III., USA
}

\section{Key Words}

Sickle cell · Small bowel ischemia $\cdot$ Necrotizing acute serositis

\begin{abstract}
We report a case of small bowel ischemia secondary to sickle cell disease. Acute bowel ischemia is an uncommon presentation of patients with sickle cell disease. Historically, only a handful of cases have been reported. We also provide a summary of the literature relevant to sickle cell patients with acute bowel ischemia.
\end{abstract}

\section{Introduction}

While abdominal pain is a common presentation in patients with sickle cell disease, its progression to an acute surgical abdomen is relatively rare. Only a few case reports describing ischemic bowel secondary to sickle cell crisis have been published. Ischemic bowel secondary to sickle cell disease has been recognized with increasing frequency [13]. Most patients with ischemic bowel are elderly and often have a past medical history significant for atherosclerotic disease manifesting with congestive heart failure or cardiac dysrhythmias. In contrast, patients with sickle cell disease are considerably younger, often with no history of cardiovascular disease [4].

\section{Case Report}

A 42-year-old African-American man with a past medical history of hypertension, end-stage renal disease, and mechanical heart valve was admitted to the hospital in sickle cell crisis with complaints of chest and bilateral upper extremity digit pain. Cardiac work-up showed an EKG with ST depression in the left lateral wall leads. Cardiac catheterization was performed, but demonstrated no significant coronary artery lesions and required no further cardiac intervention. The patient had an elevated amylase and lipase of 456 and $334 \mathrm{U} / \mathrm{l}$, respectively. Electrolytes were within normal limits except for a total bilirubin of $2.1 \mathrm{mg} / \mathrm{dl}$. This was thought to be due to biliary pancreatitis. As such, the patient was managed conservatively and eventually started on oral intake. Once the patient was started on a regular diet, he developed acute generalized abdominal pain which was similar in his estimation to previously 
experienced pain associated with sickle cell crisis. Upon examination, the patient's vital signs were within normal limits. Nevertheless, his examination revealed a tense, distended abdomen which revealed diffuse rebound tenderness and guarding. Complete blood cell count demonstrated a white blood cell count of 16,200 with 80\% neutrophils. An upright abdominal film demonstrated pneumoperitoneum. The patient was immediately given intravenous piperacillin/tazobactam, hydrated aggressively, and taken to the operating room for exploration.

Intraoperatively, evaluation of the small bowel demonstrated 3 lesions that were grossly infarcted and leaking bile. The ischemic regions and infarcted/perforated portions of duodenum and jejunum were resected with primary anastomosis. The patient also underwent cholecystectomy which revealed multiple gallstones. The patient's operative course was uneventful and he was transferred to the intensive care unit for recovery. Histologic sections of the duodenal and jejunal specimens of infarcted bowel demonstrated transmural infarction with necrotizing acute inflammatory cell exudates along with submucosal edema and necrotizing acute serositis consistent with ischemic bowel (ig. 1, fig. 2$)$.

\section{Discussion}

Abdominal pain is a common and often prominent symptom during sickle cell crisis. Its etiology has been attributed to a myriad of sources including mesenteric and retroperitoneal adenopathy, infarction in vertebral bodies, hepatobiliary disease and splenic infarction [5]. While the above may at some point in the natural history of the disease contribute to abdominal pain, it is more likely that intermittent ischemia, stemming from transient 'low-flow' states due to red blood cell deformity, is the primary source of the abdominal pain. At the capillary level, red blood cell deformability is the major determinant of viscosity with the capillary diameter at which red blood cell deformation inhibits normal blood flow being $<10 \mu \mathrm{m}$. Increased membrane rigidity resulting in decreased deformability may be the primary contributor in transient vasoocclusion in capillaries that often range in diameter from $30-60 \mu \mathrm{m}$. One classic study by Boley et al. reproduced ischemic colitis pathology in dogs after injection of microspheres of $30-100 \mu \mathrm{m}$ into the mesenteric circulation $[6,7]$.

We believe that the bowel injury found in our particular patient likely represents an extreme manifestation of what is likely to be a spectrum of pathology that ranges from minor abdominal pain secondary to transient ischemia to full-blown transmural bowel infarction. Most case reports and reviews emphasize that the majority of patients with abdominal pain will not have clinically significant bowel injury and thus can be managed conservatively with bowel rest, aggressive hydration, and intravenous analgesics. However, our case highlights the fact that the far end of the clinical spectrum, i.e. transmural bowel injury with pneumoperitoneum requiring operative intervention, does indeed occur and should be kept in mind when managing and following sickle cell patients with abdominal pain. 


\begin{tabular}{r|l|l|l} 
Case Reports $h$ & Case Rep Gastroenterol 2009;3:26-29 & Published online: March 31, 2009 & $\begin{array}{l}\text { ○ 2009 S. Karger AG, Basel } \\
\text { ISSN 1662-0631 } \\
\text { Wwww.karger.com/crg }\end{array}$ \\
\hline
\end{tabular}

Fig. 1. H\&E stain, low power, small intestine with transmural inflammation, mucosal edema.

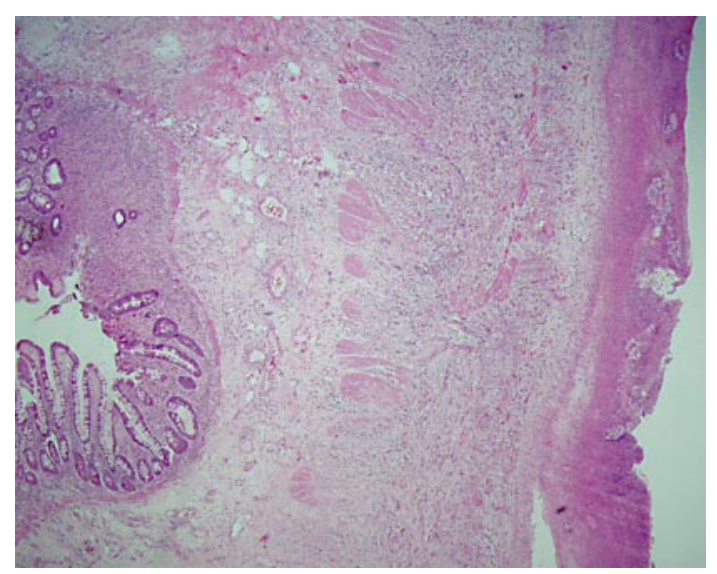

Fig. 2. H\&E stain, high power, acute inflammatory cell infiltration, necrotizing acute serositis.

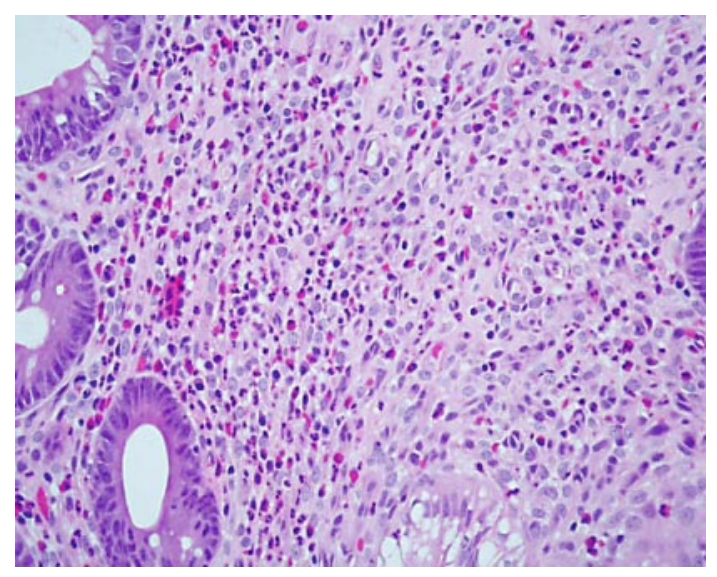




\section{References}

1 Green BT, Branch MS: Ischemic colitis in a young adult during sickle cell crisis: case report and review. Gastrointest Endosc 2003;57:605-607.

-2 Engelhardt T, Pulitzer DR, Etheredge EE: Ischemic intestinal necrosis as a cause of atypical abdominal pain in a sickle cell patient. J Natl Med Assoc 1989;81:10771088 .

-3 Moukarzel AA, Rajaram M, Sundeep A, et al: Sickle cell anemia: severe ischemic colitis responding to conservative management. Clin Pediatr (Phila) 2000;39:241243.

4 Boley SJ, Brandt LJ, Veith FJ: Ischemic disorders of the intestines. Curr Probl Surg 1978;15:1-85.

5 Crastnopol P, Stewart CF: Acute abdominal manifestations in sickle cell disease. Arch Surg 1949;59:993-1000.

-6 Boley SJ, Krieger H, Schultz L, et al: Experimental aspects of peripheral vascular occlusion of the intestine. Surg Gynecol Obstet 1965;121:789-794.

7 Akinola NO, Stevens SM, Franklin IM, et al: Subclinical ischaemic episodes during the steady state of sickle cell anaemia. J Clin Pathol 1992;45:902-906. 